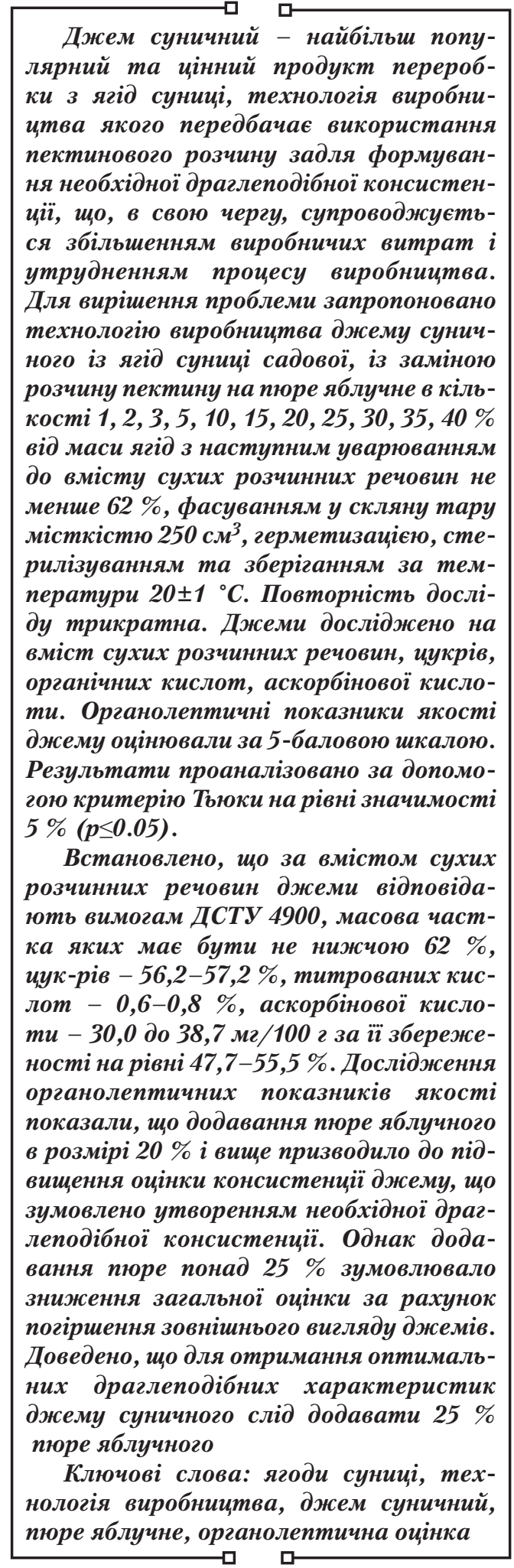

UDC 663.813:634.75

DOI: $10.15587 / 1729-4061.2019 .183723$

\title{
IMPROVEMENT OF THE TECHNOLOGY OF GARDEN STRAWBERRY JAM IN COMBI- NATION WITH APPLE PUREE
}

\author{
I. Z a morska \\ Doctor of Technical Sciences, Associate Professor, \\ Head of Department \\ Department of Technology Storage and \\ Processing of Fruits and Vegetables* \\ E-mail: zil197608@gmail.com \\ V. Z a morsk y i
}

Doctor of Agricultural Sciences, Professor, Head of Department Department of Fruit Growing and Viticulture*

Y. H a I a h u r

PhD, Senior Lecturer Department of Management*

V. O s y k a

Doctor of Technical Sciences, Associate Professor**

S. B e li n s k a

Doctor of Technical Sciences, Professor, Head of Department**

I. Motuzk a

Doctor of Technical Sciences, Professor**

T. B o z h k o

PhD, Associate Professor**

O. Krasuly a

$\mathrm{PhD}$, Associate Professor Department of Milk and Dairy Products Technology National University of Food Technologies Volodymyrska str., 68, Kyiv, Ukraine, 01601

M. F i I

$\mathrm{PhD}$, Associate Professor Department of Tourism

Ivan Franko National University of Lviv Universytetska str., 1, Lviv, Ukraine, 79000 *Uman National University of Horticulture

Instutytska str., 1, Uman, Ukraine, 20300

**Department of Commodity Science, Safety and Quality Management

Kyiv National University of trade and Economics Kyoto str., 19, Kyiv, Ukraine, 02156

\section{Introduction}

Garden strawberry is the most widespread berry culture in the world due to the high economic efficiency of cultivation and processing, harmonious taste and attractive, pronounced aroma with fruit, floral, herbal, sweet or caramel notes. The aroma of strawberries is formed under the influence of a significant number of volatile compounds, mainly, complex esters (from 25 
to $90 \%$ of the total amount of volatile compounds), aldehydes and furanons, the share of which can reach up to $50 \%[1,2]$.

Harmonious taste of strawberry berries is provided by the combination of sugars, the weight fraction of which in berries is $5.3-9 \%$, which are represented by glucose, fructose and sucrose [3] and organic acids (up to $1.3 \%$ ), with citric and malic acids $[4,5]$ dominating among them with a significant prevalence of citric acid.

Strawberries have high antioxidant capacity thanks to a significant content of ascorbic acid (up to $104.5 \mathrm{mg} / 100 \mathrm{~g}$ ), the biological role of which is to protect the body from oxidative stress [6].

A significant antioxidant potential of garden strawberries is also due to the significant proportion of phenolic compounds, in particular, anthocyans, flavonoids and phenolic acids [7], the amount of which, according to different data, ranges from 159 to $289 \mathrm{mg} / 100 \mathrm{~g}$. In paper [8], it was established that in the anthocyan complex of strawberry, there prevails pelargonidine 3-glucoside, which accounts for up to $90 \%$ of the total amount. Due to the existence of ellagic acid, the content of which is up to $51 \%$ of the total number of phenolic compounds, strawberry has a potential chemoprophylactic, anti-inflammatory and antibacterial effect [9].

Strawberries are consumed fresh and used for the production of compotes, jams, juices, puree and other kinds of products, with the significant preserved antioxidant ability [3, 10, 11].

Strawberry jam is the most popular product of strawberry processing, thanks to the attractive red color and high organoleptic properties. The strawberries of such varieties as Korona, Honeoye, Polka [12], Jonsok, and Senga Sengana are recommended to be used for high quality jam [13].

Paper [14] contains the results of research into strawberry jam. It was shown that strawberry jams are a valuable source of biologically active substances with a significant antioxidant potential due to high preservation of phenolic compounds [15]: at the level of $90.7-92.4 \%$ of their content in fresh berries. [16]. It was proven [9] that during processing and storage of strawberry jam the content of ellagic acid in it increases significantly due to the release of hexahydroxydiphenyl acid from elagitanins, which turns into ellagic acid.

One of the main characteristics of jam is the formation of viscous jelly-like consistency resulting from the interaction of sugar with pectin in the presence of significant quantities of fibers and all components of cell walls [17].

The high capability to change consistency at almost every stage of processing is considered [18] one of the main problems of processing strawberries, the nature of the change of which is significantly influenced by the stage of maturity, method and degree of mechanical treatment of berries. Microscopic studies of fruit parts from strawberry jam showed the integrity of the only epidermal and vascular tissues during thermal treatment of jam, whereas, parenchyma and the hypodermal cells are plasmolized and their cell walls are ruined.

The traditional production technology of strawberry jam implies boiling fresh or frozen strawberries with sugar syrup or dry sugar with the addition of pectin solution $[19,20]$.

\section{Literature review and problem statement}

Pectin is the main factor determining consistency of jam [21]. However, there remained unsolved issues associat- ed with the possibility of replacing the pectin solution with more affordable fruit and berry raw materials, which ensures the formation of viscous jelly-like consistency.

The use of pectin solution in the production of jams predetermines objective difficulties, associated with the growth of energy and material production costs, accompanied by an increase in the cost of the product. This complicates the organization of jam production due to the need for additional process of preparation of the pectin solution by mixing pectin with sugar or powdered sugar and dissolving in water to obtain a homogeneous mass. It should be noted that in order to achieve jelly-forming conditions, when adding type A pectin or imported citric pectin, the optimum $\mathrm{pH}$ zone is $3.0-3.3$, however, $\mathrm{pH}$ of strawberries fluctuates within $3.2-3.5$, which leads to the additional application of citric or wine acid. In papers [21, 22], it was established that an increase in the pectin concentration causes negative changes in the color intensity of jams.

The data obtained in paper [23] indicate darkening of strawberry jam coloration when adding food fibers of peach. An increase in the amount of dietary fiber led to deterioration of product coloration.

An alternative method [24] for the grapefruit jam production is to add bamboo fiber along with pectin to improve the consistency of jams, however, this method involves using the components that are difficult to obtain in the processing industry of Ukraine.

Paper [25] contains the findings of the research into the quality of pomegranate jam with the substitution of commercial pectin with other jelly-forming agents, such as powder from the pomegranate skin, pectin and fibers of pomegranate skins. However, the authors underline the deterioration of sweetness, color and consistency of finished jams.

The option of solving the problem may be the use of food additives. This approach is used in [26], where it was proposed to use xanthane gum and inulin as thickeners in the production of strawberry jam. However, the specified technology does not solve the problem of complete replacement of pectin solution in the production of jams. The authors proved the possibility of replacement of only $25 \%$ of the formulation amount of pectin without significant changes in the organoleptic properties of the product.

The known way of overcoming the problem in the production of strawberry jam is the replacement of the pectin solution with gelling juice from apples, quince or gooseberry with a high content of pectin. However, this leads to additional power consumption due to an increase in duration of jam boiling to obtain the required jelly-like consistency and complication of the manufacturing process [19].

All this makes it possible to argue that it is appropriate to conduct research dedicated to the improvement of the production technologies of strawberry jam without using pectin or other food additives. In order to solve the problem in the production of strawberry jam, we proposed to use apple puree. The fact that apples as raw materials for the industrial production of puree are cheap and easily available makes it appropriate to replace pectin, which is not produced in the country. In addition, the use of apple puree in the production of strawberry jam will promote the development of domestic producers of fruit and berry puree and expansion of the range of jams. 


\section{The aim and objectives of the study}

The aim of this study was to improve the technology of strawberry jam by adding apple puree to obtain viscous jelly-like consistency.

To accomplish the aim, the following tasks have been set:

- to study the quality indicators of the developed variants of strawberry jam and to evaluate their conformity with DSTU 4900 "Jams. Technical conditions";

- to identify the specific features of the formation of organoleptic quality indicators of strawberry jam at various proportion of apple puree;

- to establish the proportion of apple puree, which is necessary for the formation of viscous jelly-like consistency of strawberry jam taking into consideration the requirements of DSTU 4900 “Jams. Technical conditions".

\section{Materials and methods to study the influence of apple puree on the physical- chemical and organoleptic properties of strawberry jam}

\section{1. Preparation of jam}

The studies were conducted in 20142015 at the Department of Storage and Processing of Fruits and Vegetables of Uman National University of Horticulture, Uman, Ukraine. Completely ripe berries of the strawberry of Ducat variety were collected and transported to the laboratory not later than one hour after harvesting. Before jam preparation, berries were stored in a refrigerator for 1-2 hours at the temperature of $0 \pm 1{ }^{\circ} \mathrm{C}$ and relative humidity of $96 \pm 1 \%$.

Sterilized strawberry jam ("control” variant) was produced under laboratory conditions according to the technological scheme, which included the technological operations: sorting berries, washing, clearing of stems and sepals, and inspection. After that prepared raw materials were mixed with dry sugar and boiled. 5-10 minutes before the end of boiling, the pectin solution of the concentration of $0.3 \%$ of the product weight was added and boiled until the content of dry matter in the finished product is not less than $62 \%$.

The experimental variants of jam were produced according to the developed technological scheme (Fig. 1), which included replacing the pectin solution with apple puree in the amount of $1,2,3,5,10,15,20$, $25,30,35$ and $40 \%$ of the weight of berries.

Technological operations in preparation of strawberries and sugar are similar to those of the traditional scheme: sorting berries for the purpose of removal of the samples damaged and affected by pests and diseases, washing at water pressure of $0.1-0.15 \mathrm{MPa}$, clearing from stems and sepals, and inspection. The prepared strawberries were mixed with dry sugar and boiled. Apple puree was added
5-10 minutes before the end of boiling. Jam was boiled at residual pressure in the working chamber of $35-48 \mathrm{kPa}$ and at steam pressure of 202-253 kPa until the content of dry soluble substances is not less than $62 \%$ and packaged at the temperature of $70 \pm 2{ }^{\circ} \mathrm{C}$ in glass containers with the capacity of $250 \mathrm{~cm}^{3}$, sealed $\left(P_{\text {vacuum }}=47-54 \mathrm{kPa}\right)$, the tightness was checked (critical pressure of $0.01-0.02 \mathrm{MPa}$ ), sterilized and cooled at the mode of $\frac{30}{98^{\circ} \mathrm{C}} \cdot \frac{10}{75^{\circ} \mathrm{C}} \cdot \frac{10}{45^{\circ} \mathrm{C}} \cdot \frac{5}{20{ }^{\circ} \mathrm{C}} \cdot 5($ air $)$. The experiment was repeated thrice.

Apple puree was produced during harvesting of apples and stored to use in the production of jam. The apples were sorted, washed at water pressure of $0.2-0.3 \mathrm{MPa}$, inspected, crushed, blanched by steam for $3-5$ minutes, pulped through a sieve with the diameter of holes of $1.5-2.0 \mathrm{~mm}$, and then through a sieve with the diameter of $0.8 \mathrm{~mm}$, puree was packaged in containers, sterilized and stored.

\section{$\underline{\text { Strawberry }}$}

Transportation

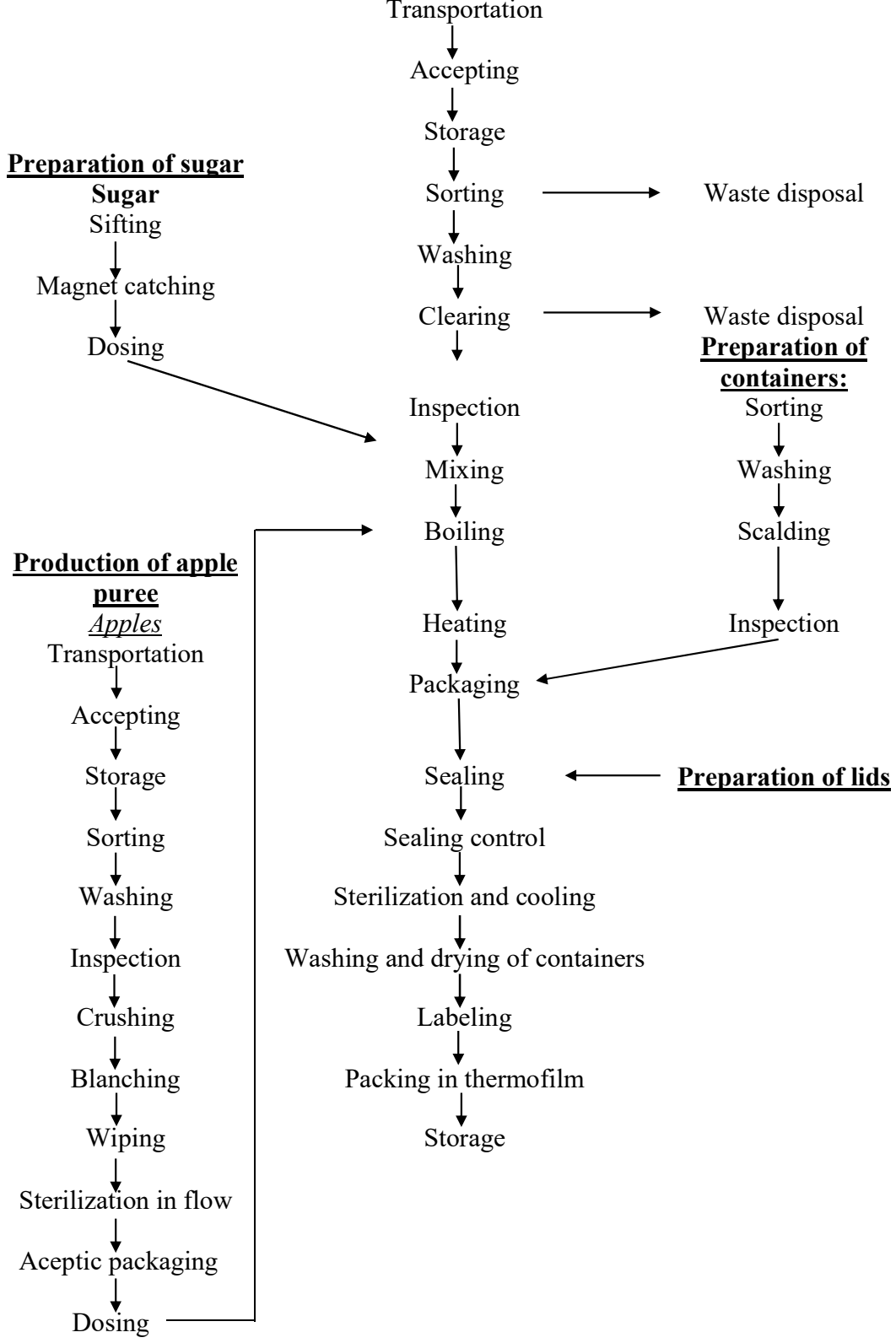

Fig. 1. Developed technological scheme of production of cans "Sterilized strawberry jam" 


\subsection{Methods for determining the quality indicators of jam}

The content of dry soluble substances was determined in finished jams by the electronic refractometer of the Pal-1 type (Japan), the contect of sugars - by the spectrophotometric method [27, 28], of titrated acids - by titration of alkali [28], of ascorbic acid - by the Tilmans method [29].

Organoleptic quality indicators of strawberry jam, such as appearance, consistency, color, taste and smell and the general estimate were determined by 10 tasters by the 5 -point scale, where 5 points mean the excellent quality.

Statistical analysis was performed using program StatSoft STATISTICA 6.1.478 Russian, Enterprise Single User (2007)

\section{Results of research into strawberry jam}

5. 1. Chemical composition of strawberry jam

The results of determining the main indicators of chemical composition of raw materials and of semi-finished products for the production of strawberry jam are presented in Table 1.

It should be noted that strawberries berries accumulated $7.7 \%$ less dry soluble substances, $5.1 \%$ less sugars in comparison with apples, during the research period, on average according to the least significant difference $\left(\mathrm{HIP}_{05}\right)$ between the variants of the experiment at the $5 \%$ probability level. However, the content of organic substances in them was by $0.5 \%$ higher and they had significant vitamin value due to the content of ascorbic acid that was 4 times higher.

The chemical composition of apple puree differed from similar indicators of apples due to the removal of non-edible parts, skins and coarse fibers as a result of pulping. In this case, we established a decrease in weight fraction of dry soluble substances by $0.6 \%$, of sugars - by $0.2 \%$, of organic acids - by $0.1 \%$, and the loss of ascorbic acid amounted to $8.3 \%$ from their content in fresh apples.
In order to reduce production costs in manufacturing strawberry jam, we developed formulations with the replacement of strawberries with apple puree by $1,3,5,10,15,20,25$, 30,35 and $40 \%$, which made it possible to study the effect of all possible concentrations of apple puree. The increase in the fraction of apple puree in the jams by over $40 \%$ will cause the need to change the product name to "Strawberry and apple jam".

To establish the rational dosage of apple puree, taking into consideration the requirements of DSTU 4900 "Jams. Technical conditions", we studied the basic indicators of the chemical composition of research samples of strawberry jam, which was proved by the methods of dispersive analysis (Fig. 2).

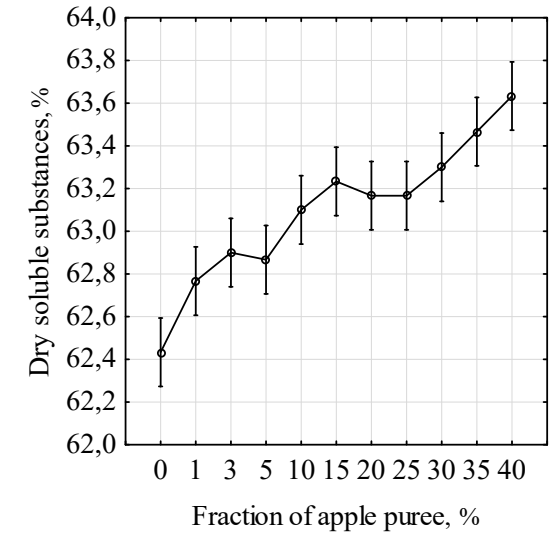

$a$

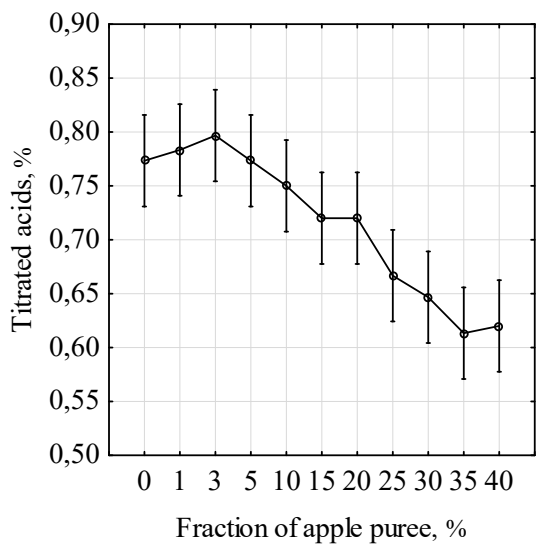

c

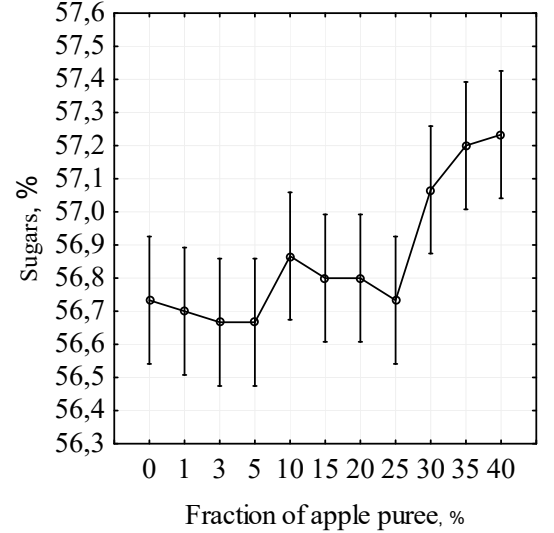

$b$

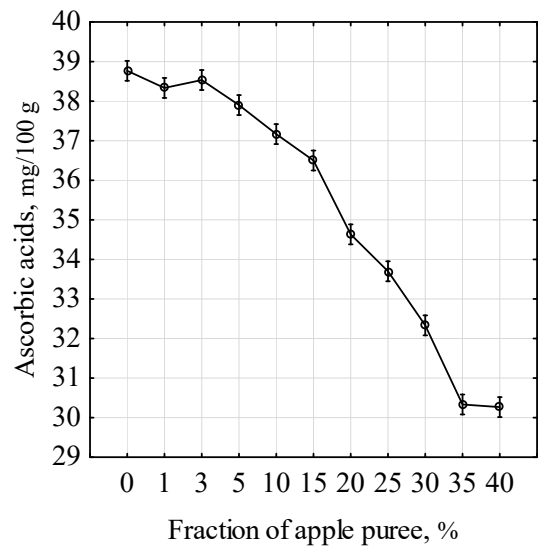

$d$

Fig. 2. Results of dispersion analysis of dependence of chemical composition of strawberry jam on the fraction of apple puree at reliability level of 0.95: $a-$ dry soluble substances; $b$ - sugars; $c$ - titrated acids; $d$ - ascorbic acid

Table 1

Chemical composition of raw materials and semi-finished products

\begin{tabular}{|c|c|c|c|c|}
\hline \multirow[b]{2}{*}{$\begin{array}{l}\text { Raw material } \\
\text { and semi-fin- } \\
\text { ished product }\end{array}$} & \multicolumn{3}{|c|}{ Weight fraction, \% } & \multirow{2}{*}{$\begin{array}{l}\text { Content } \\
\text { of ascor- } \\
\text { bic acid, } \\
\mathrm{mg} / 100 \mathrm{~g}\end{array}$} \\
\hline & $\begin{array}{c}\text { dry } \\
\text { soluble } \\
\text { substances }\end{array}$ & sugars & $\begin{array}{c}\text { organic } \\
\text { acids }\end{array}$ & \\
\hline Strawberries & $10.1 \pm 0.18$ & $8.9 \pm 0.20$ & $1.0 \pm 0.02 *$ & $99.5 \pm 0.44$ \\
\hline Apples & $17.8 \pm 0.15$ & $14.0 \pm 0.11$ & $0.5 \pm 0.01 * *$ & $24.0 \pm 0.17$ \\
\hline Apple puree & $17.2 \pm 0.13$ & $13.8 \pm 0.13$ & $0.4 \pm 0.01^{* *}$ & $22.0 \pm 0.18$ \\
\hline $\mathrm{HIP}_{05}$ & 0.7 & 0.6 & 0.1 & 0.6 \\
\hline
\end{tabular}

Note: * - in terms of citric acid; * *-in terms of malic acid
Fig. 2 shows that the content of dry soluble substances in the studied samples of strawberry jam varied insignificantly and fluctuated within $62.3-63.7 \%$ due to jam boiling to the level of dry soluble substances of not less than $62 \%$. The results are quite consistent with the requirements of the State standard of Ukraine 4900 "Jams. Technical conditions".

The weight fraction of sugars in the samples of jam was $56.2-57.2 \%$ (Fig. 2, b). It is necessary to note the dependence of the mass fraction of sugars in the research samples of jam on the fraction of apple puree: an increase in the amount of the latter led to an increase in sugar content. The obtained result is explained by the higher weight fraction of sugars in apple puree, compared with strawberries. The dis- 
crepancy in the range from $0.1 \%$ to $0.3 \%$ of sugars between the specified variants is not significant and is caused by boiling with the non-essential difference in the content of dry soluble substances in the product, but this amount was not lower than $62 \%$, which meets the requirements of the standard.

Instead, we observed the opposite tendency regarding the changein the weight fraction of titrated acidsinjams (Fig. 2,c), the level of which ranged from 0.6 to $0.8 \%$. An increase in the fraction of apple puree in the product led to a decrease in acidity of the jam, because titrated acidity of apple puree was significantly lower in comparison with strawberries. A significant difference in the level of titrated acids in jams was observed when adding the fraction of apple puree in the amount of $15 \%$ and higher. A divergence in the content of titrated acids is less than $0.05 \%$, which is not significant for the indicator given with accuracy of up to 0.1 , is not significant between the variants and corresponds to the acceptable error of the experiment.

The content of ascorbic acid in the research samples of the jam ranged from 30.0 to $38.7 \mathrm{mg} / 100 \mathrm{~g}$. In this case, there is an inverse dependence of its content in the jam on the formulation fraction of apple puree. A substantially higher content of ascorbic acid was found in the samples with a fraction of apple puree of not more than $10 \%$. A decrease in the content of ascorbic acid in the samples of jam compared with fresh berries (Table 1) is explained by lengthy thermal treatment of the product, but its preservation in the finished products was 47.7-55.5\% (Fig. 2, $d$ ).

\section{2. Organoleptic quality indicators of strawberry jam}

To determine the quality of strawberry jam for various fraction of apple puree, we carried out the closed tasting of finished samples of products. In order to visualize the obtained data, we constructed the diagrams of projections of obtained scores, depending on the fraction of apple puree in the program StatSoft STATISTICA 6.1.478 with the pitch of the fraction of apple puree of $5 \%$.
The studies revealed significant differences in organoleptic estimation of the research samples of jams, depending on the formulation fraction of apple puree in the product. Thus, the appearance of the research samples of jams, which were made according to the developed technology, was evaluated by the tasters at 3.7-4.92 points. The highest scores for the jam appearance were obtained at the fraction of apple puree of up to $25 \%$ inclusive due to the gradual formation of the jelly-like consistency (Fig. 3). However, exceeding its amount by more than $25 \%$ led to a decrease in score by 0.3-0.7 points due to the deterioration of the product coloration. In this case, the appearance of jam, manufactured by traditional technology (control) was rated at 4.8 points, while the score of the jam with $25 \%$ of apple puree was by 0.12 points higher.

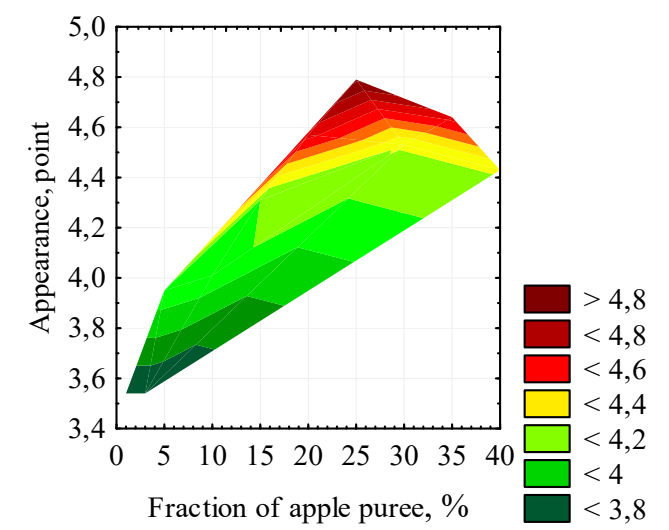

a

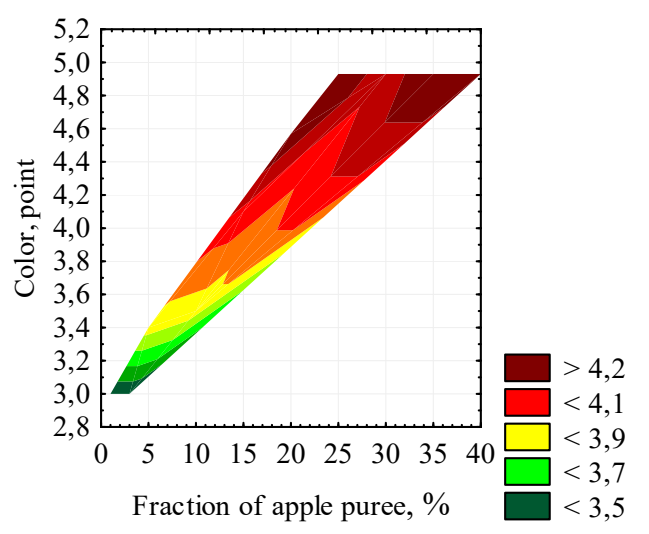

c

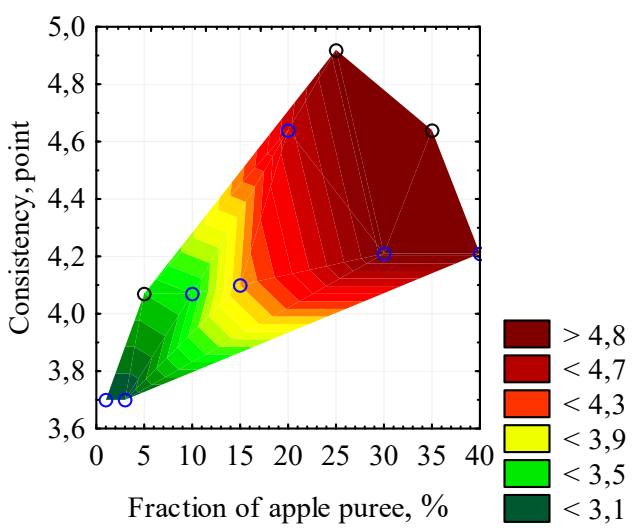

$b$

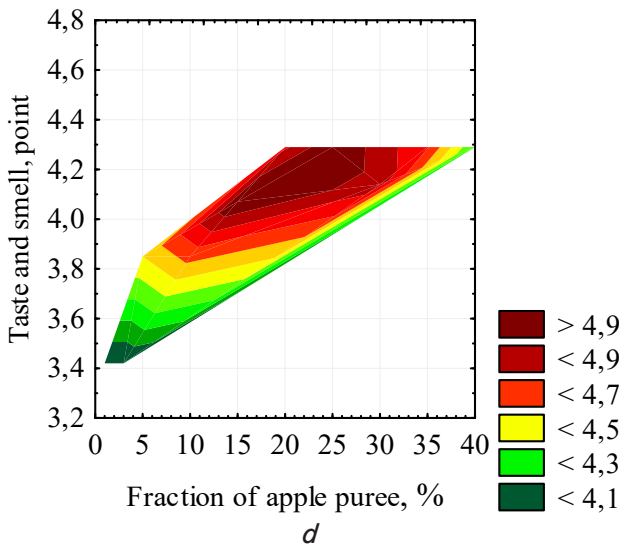

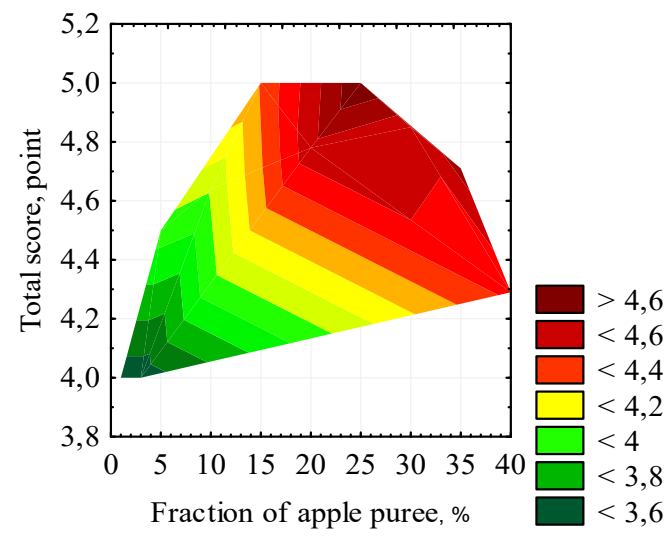

e

Fig. 3. Organoleptic assessment of strawberry jam: $a$ - appearance; $b$ - consistency; $c-$ color; $d-$ taste and smell; $e-$ total score, point 
The consistency of the research samples of strawberry jam scored 3.0-4.93 points, while the control variant scored 4.5 points (Fig. $3, b$ ). It was established that the jam samples with the use of apple puree in the amount of $20 \%$ and more had the score for consistency at the level of control and substantially higher due to the formation of the necessary jelly-like consistency.

The color of the studied jam samples was given 3.4-7.7 points by the tasters (Fig. $3, c$ ). The color of the strawberry jam with the addition of the fraction of apple puree at the level of $15-25 \%$ was estimated as high. However, there was a difference in the estimation of color of the developed variants of jam from the control, which was caused by the presence of apple puree.

The taste and the smell of the studied samples of the product scored 4.0-5.0 points (Fig. 3, d). The taste and smell of the samples of strawberry jam made with the replacement of the fraction of strawberries with $15-30 \%$ of apple puree was estimated at the level of control and higher and scored $4.8-5.0$ points.

The total organoleptic score of the jam samples, produced by traditional and developed technologies substantially depended on the fraction of apple puree in the product: the increase in the fraction of the latter up to $25 \%$ led to an increase in the total organoleptic score (Fig. 3,e). Instead, an increase in the fraction of puree over $25 \%$ caused a decrease in the overall score of the jam due to the deterioration in appearance. The highest overall score was received by jams with $25 \%$ of apple puree -4.79 points, which is by 0.09 points higher that the control.

The correlations were found in the strawberry jam made according to the proposed technology, depending on the fraction of apple puree (Table 2, Fig. 4).

Table 2

Predicted model of estimation of consistency and overall score of strawberry jam

\begin{tabular}{|c|c|c|}
\hline Indicator, point & Predicted model & $R^{2}$ \\
\hline Consistency & $3.4066+0.0452 \cdot x^{*}$ & $0.80 \pm 0.2$ \\
\hline Total score & $3.9529+0.192 \cdot x$ & $0.60 \pm 0.04$ \\
\hline
\end{tabular}

Note: * $x$ - fraction of apple puree, $\%$

In order to objectively establish a rational dosage of apple puree, taking into consideration the requirements of DSTU 4900 "Jams. Technical conditions", we used the method for estimation of predicted values and construction of desirability function by the organoleptic indicators of jam quality (Fig. 5).

The limiting criteria were organoleptic indicators of the quality of strawberry jam: high indicators of appearance, consistency, color, taste and smell, overall score of the jam samples. The minimal admissible score of the indicator of appearance was 3.7, the maximum admissible score was 4.92, score of consistency, respectively 3.0 and 4.93 , of color -3.42 and 4.29 , taste and smell -4.0 and 5.0, overall score -3.54 and 4.79 points.

The obtained results indicate that the optimum amount of apple puree, which should be added in the production of strawberry jam to form the necessary organoleptic quality indicators, is from 25 to $28.3 \%$, in this case the requirements set for the quality of the finished product are met by $88 \%$. Addition of an apple puree in the amount of less than 25 and over $28.3 \%$ does not meet the requirements that are set for the model.

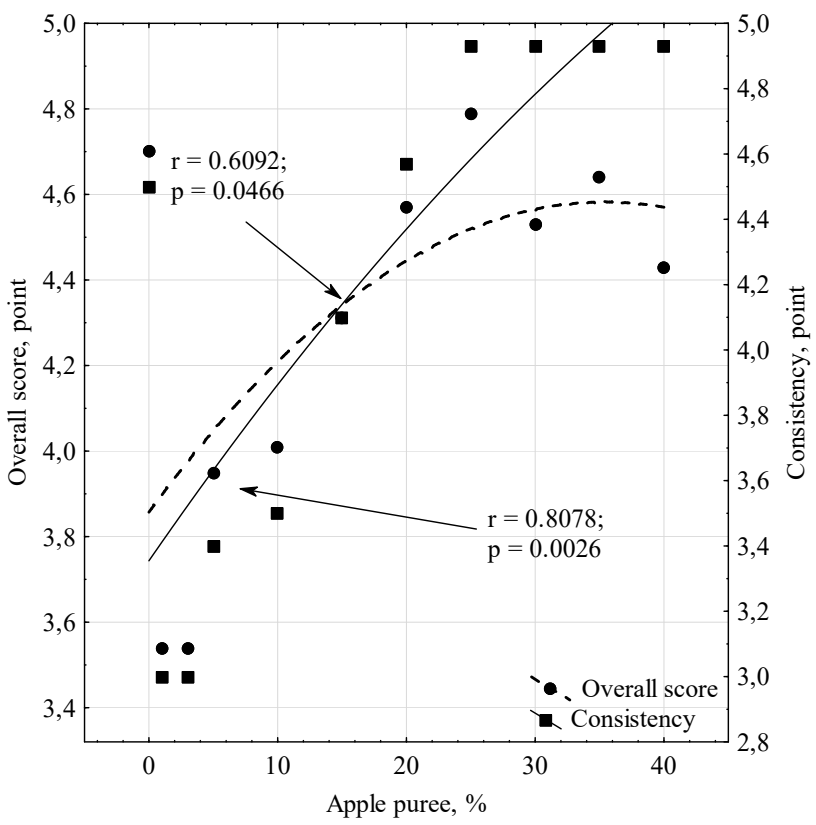

Fig. 4. Correlation dependence of consistency and overall score of strawberry jam of strawberry jam on the fraction of apple puree

Desirability
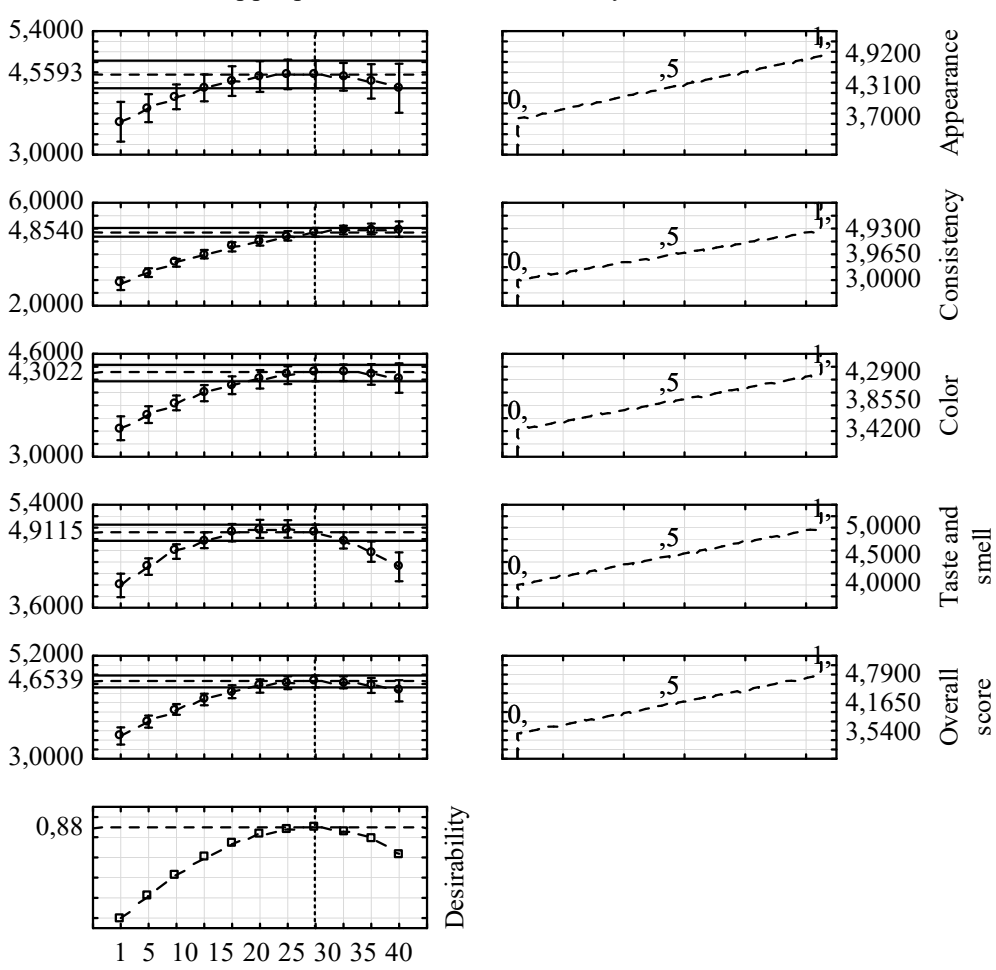

Fig. 5. Profile of predicted values and desirability function based on the organoleptic indicators of strawberry jam quality, depending on fraction of apple puree 


\section{Discussion of results of research into the jam from garden strawberries with the addition of apple puree}

In order to solve the problem of the increase in power and material production costs and complication of organization of manufacturing strawberry jam produced by the traditional technology with the use of the pectin solution, the possibility of replacing the latter with apple puree was studied.

The main indicators of the chemical composition of raw materials and semi-finished products for the production of strawberry jam were established (Table. 1). Strawberry accumulated $10.1 \%$ of dry soluble substances, $8.9 \%$ of sugars, $1.0 \%$ of organic acids, $99.5 \mathrm{mg} / 100 \mathrm{~g}$ of ascorbic acid. $17.8 \%$ of dry soluble substances, $14.0 \%$ of sugars, $0.5 \%$ of organic acids and $24 \mathrm{mg} / 100 \mathrm{~g}$ of ascorbic acid were found in apples. We established a decrease in the content of main indicators of the chemical composition of apple puree as a result of pulping through the removal of non-edible parts, skins and coarse fibers.

The statistical analysis reliably revealed the positive effect of using apple puree on the formation of the necessary physical-chemical and organoleptic indicators of the quality of strawberry jam taking into account the requirements of DSTU 4900 "Jams. Technical conditions" (Fig. 2). The content of dry soluble substances in jams was found at the level of $62.3-63.7 \%$, of sugars $56.2-57.2 \%$, of titrated acids $-0.4-0.5 \%$. In this case, the preservation of ascorbic acid in finished products was $47.7-55.5 \%$

According to DSTU 4900 "Jams. Technical conditions", the quality of jams was assessed by the following physico-chemical indicators: weight fraction of dry soluble substances, the weight fraction of titrated acids (are normalized not less than...), weight fraction: sorbic acid, of sulfur anhydride (provided that they are added into the product), weight fraction of mineral and vegetable impurities (are normalized in the quantity of not more than...). This article deals with the weight fraction of dry soluble substances and titrated acids, which makes it possible to call these indicators necessary.

Organoleptic indicators of the quality of canned goods, including consistency, are evaluated according to GOST 8756.1-79 "Canned food products. The methods for determining the organoleptic indicators" involve subjective evaluation by tasters using the senses organs and do not imply the research into fluidity and viscosity of the system. The indicators of fluidity and viscosity of the system are not included in DSTU 4900 "Jams. Technical conditions", hence the interpretation of the better and worse results will be complicated.

The research results shown in Fig. 3 indicate the possibility of using apple puree to replace the pectin solution. It was established that the research samples of the strawberry jam produced according to the developed technology differed significantly, depending on the fraction of apple puree. Thus, the addition of apple puree of up to $25 \%$ inclusively contributed to the increase in the score of the product ap- pearance, and the excess of this amount, on the contrary, had a negative influence.

The samples of jam with the fraction of apple puree of $20 \%$ or more had a high score for consistency, whereas the limit of the fraction of puree in the range from 15 to $25 \%$ resulted in a high score for color, taste and smell of the jam.

The overall organoleptic score of the jam quality gradually increased until achieving $25 \%$ puree fraction in the product and its exceeding caused a decrease in the score.

The studies established that for the production of strawberry jam according to the developed technology, it is rational to add $25 \%$ of apple puree, which contributes to the formation of viscous jelly-like consistency of jams in accordance with the requirements of DSTU 4900 "Jams. Technical conditions" and increases the score of appearance, taste and smell of the product to the level of control and higher.

With the use of desirability function (Fig. 5), it was proved reliably that thanks to the use of $25 \%$ of apple puree for the production of strawberry jam, the requirements of DSTU 4900 "Jams. Technical conditions" are satisfied.

The advantage of this study is the possibility to produce strawberry jam without the addition of the pectin solution, jelling juice or thickeners. The obtained results can be used in the production of jams from other types of fruits and berries. However, the fact that the choice of substitutes for the pectin solution from the assortment of fruit and berry raw materials grown in Ukraine is limited can be considered a drawback.

Subsequent research will be aimed at finding new rational variants for replacing the pectin solution in the production of jams and at studying their impact on the quality of the finished product.

\section{Conclusions}

1. The indicators of quality of the developed variants of strawberry jam with addition of apple puree by their physico-chemical indicators meet the requirements of DSTU 4900 "Jams. Technical conditions". The content of dry soluble substances in finished jams is $62.0-64.0 \%$ at the permissible level of not less than $62 \%$. The weight fraction of sugars was established at the level of $56.2-57.2 \%$, titrated acids $-0.4-0.5 \%$ at the admissible level of not less than $0.2 \%$, preservation of ascorbic acid $-47.7-55.5 \%$.

2. The introduction of $25 \%$ of apple puree to the formulation of strawberry jam contributes to the improvement of jam appearance and to the formation of the necessary jelly-like consistency. Exceeding its amount by more than $25 \%$ leads to deterioration in the coloration of the product. Addition of $15-25 \%$ of apple puree preserves color, taste and smell inherent in strawberry jam.

3. To form viscous jelly-like consistency of strawberry jam, taking into consideration the requirements of DSTU 4900 "Jams. Technical conditions", the fraction of apple puree is $25 \%$ of the formulation amount of strawberries.

\section{References}

1. Yan, J., Ban, Z., Lu, H., Li, D., Poverenov, E., Luo, Z., Li, L. (2018). The aroma volatile repertoire in strawberry fruit: a review. Journal of the Science of Food and Agriculture, 98 (12), 4395-4402. doi: https://doi.org/10.1002/jsfa.9039 
2. Parra-Palma, C., Úbeda, C., Gil, M., Ramos, P., Castro, R. I., Morales-Quintana, L. (2019). Comparative study of the volatile organic compounds of four strawberry cultivars and it relation to alcohol acyltransferase enzymatic activity. Scientia Horticulturae, 251, 65-72. doi: https://doi.org/10.1016/j.scienta.2019.03.017

3. Akšić, M. F., Tosti, T., Sredojević, M., Milivojević, J., Meland, M., Natić, M. (2019). Comparison of Sugar Profile between Leaves and Fruits of Blueberry and Strawberry Cultivars Grown in Organic and Integrated Production System. Plants, 8 (7), 205. doi: https:// doi.org/10.3390/plants8070205

4. Gabriel, A., Resende, J. T. de, Zeist, A. R., Resende, L. V., Resende, N. C., Zeist, R. A. (2019). Phenotypic stability of strawberry cultivars based on physicochemical traits of fruits. Horticultura Brasileira, 37 (1), 75-81. doi: https://doi.org/10.1590/ s0102-053620190112

5. Mahmood, T., Anwar, F., Abbas, M., Boyce, M. C., Saari, N. (2012). Compositional Variation in Sugars and Organic Acids at Different Maturity Stages in Selected Small Fruits from Pakistan. International Journal of Molecular Sciences, 13 (2), $1380-1392$. doi: https://doi.org/10.3390/ijms13021380

6. Patras, A., Brunton, N. P., Da Pieve, S., Butler, F. (2009). Impact of high pressure processing on total antioxidant activity, phenolic, ascorbic acid, anthocyanin content and colour of strawberry and blackberry purées. Innovative Food Science \& Emerging Technologies, 10 (3), 308-313. doi: https://doi.org/10.1016/j.ifset.2008.12.004

7. Xu, P., Zawora, C., Li, Y., Wu, J., Liu, L., Liu, Z. et. al. (2018). Transcriptome sequencing reveals role of light in promoting anthocyanin accumulation of strawberry fruit. Plant Growth Regulation, 86 (1), 121-132. doi: https://doi.org/10.1007/s10725018-0415-3

8. Da Silva, F. L., Escribano-Bailón, M. T., Pérez Alonso, J. J., Rivas-Gonzalo, J. C., Santos-Buelga, C. (2007). Anthocyanin pigments in strawberry. LWT - Food Science and Technology, 40 (2), 374-382. doi: https://doi.org/10.1016/j.lwt.2005.09.018

9. Patras, A., Brunton, N. P., Tiwari, B. K., Butler, F. (2009). Stability and Degradation Kinetics of Bioactive Compounds and Colour in Strawberry Jam during Storage. Food and Bioprocess Technology, 4 (7), 1245-1252. doi: https://doi.org/10.1007/ s11947-009-0226-7

10. Ertan, K., Türky1lmaz, M., Özkan, M. (2018). Effect of sweeteners on anthocyanin stability and colour properties of sour cherry and strawberry nectars during storage. Journal of Food Science and Technology, 55 (10), 4346-4355. doi: https://doi.org/10.1007/ s13197-018-3387-4

11. Salamon, B., Farkas, V., Kenesei, G., Dalmadi, I. (2017). Effect of added sugar and ascorbic acid on the anthocyanin content of high pressure processed strawberry juices during storage. Journal of Physics: Conference Series, 950, 042005. doi: https://doi.org/ 10.1088/1742-6596/950/4/042005

12. Wicklund, T., Rosenfeld, H. J., Martinsen, B. K., Sundfør, M. W., Lea, P., Bruun, T. et. al. (2005). Antioxidant capacity and colour of strawberry jam as influenced by cultivar and storage conditions. LWT - Food Science and Technology, 38 (4), 387-391. doi: https:// doi.org/10.1016/j.lwt.2004.06.017

13. Spayd, S. E., Morris, J. R. (1981). Influence of Immature Fruits on Strawberry Jam Quality and Storage Stability. Journal of Food Science, 46 (2), 414-418. doi: https://doi.org/10.1111/j.1365-2621.1981.tb04873.x

14. Da Silva Pinto, M., Lajolo, F. M., Genovese, M. I. (2007). Bioactive Compounds and Antioxidant Capacity of Strawberry Jams. Plant Foods for Human Nutrition, 62 (3), 127-131. doi: https://doi.org/10.1007/s11130-007-0052-x

15. Mazur, S. P., Nes, A., Wold, A.-B., Remberg, S. F., Martinsen, B. K., Aaby, K. (2014). Effects of ripeness and cultivar on chemical composition of strawberry (Fragaria $\times$ ananassa Duch.) fruits and their suitability for jam production as a stable product at different storage temperatures. Food Chemistry, 146, 412-422. doi: https://doi.org/10.1016/j.foodchem.2013.09.086

16. Bursać Kovačević, D., Levaj, B., Dagović-Uzelac, V. (2009). Free radical scavenging activity and phenolic content in strawberry fruit and jam. Agriculturae Conspectus Scientificus, 74 (3), 155-159.

17. Figuerola, F. (2007). Berry jams and jellies. Food Science and Technology, 367-386. doi: https://doi.org/10.1201/9781420006148.ch13

18. Suutarinen, J., Honkapää, K., Heiniö, R.-L., Autio, K., Mokkila, M. (2000). The Effect of Different Prefreezing Treatments on the Structure of Strawberries Before and After Jam Making. LWT - Food Science and Technology, 33 (3), 188-201. doi: https://doi.org/ $10.1006 /$ fstl.2000.0638

19. Sbornik tehnologicheskih instruktsiy po proizvodstvu konservov (1992). Vol. II. Konservy fruktovye. Ch. I. Moscow: Petit, 372.

20. Holzwarth, M., Korhummel, S., Siekmann, T., Carle, R., Kammerer, D. R. (2013). Influence of different pectins, process and storage conditions on anthocyanin and colour retention in strawberry jams and spreads. LWT - Food Science and Technology, 52 (2), 131-138. doi: https://doi.org/10.1016/j.lwt.2012.05.020

21. Kopjar, M., Piližota, V., Tiban, N. N., Šubarić, D., Babić, J., Ačkar, Đ., Sajdl, M. (2009). Strawberry jams: influence of different pectins on colour and textural properties. Czech Journal of Food Sciences, 27 (1), 20-28. doi: https://doi.org/10.17221/95/2008-cjfs 
22. Massoud, M. I., Abd El-Razek, A. M., El-yemany, I. M. (2018). Influence of xanthan gum and inulin as thickening agents for jam production. Egypt. J. Food Sci., 46, 43-54.

23. Grigelmo-Miguel, N., Gorinstein, S., Martín-Belloso, O. (1999). Characterisation of peach dietary fibre concentrate as a food ingredient. Food Chemistry, 65 (2), 175-181. doi: https://doi.org/10.1016/s0308-8146(98)00190-3

24. Igual, M., Contreras, C., Martínez-Navarrete, N. (2014). Colour and rheological properties of non-conventional grapefruit jams: Instrumental and sensory measurement. LWT - Food Science and Technology, 56 (1), 200-206. doi: https://doi.org/10.1016/ j.lwt.2013.10.038

25. Abid, M., Yaich, H., Hidouri, H., Attia, H., Ayadi, M. A. (2018). Effect of substituted gelling agents from pomegranate peel on colour, textural and sensory properties of pomegranate jam. Food Chemistry, 239, 1047-1054. doi: https://doi.org/10.1016/ j.foodchem.2017.07.006

26. Dervisi, P., Lamb, J., Zabetakis, I. (2001). High pressure processing in jam manufacture: effects on textural and colour properties. Food Chemistry, 73 (1), 85-91. doi: https://doi.org/10.1016/s0308-8146(00)00289-2

27. Jham, G. N., Fernandes, S. A., Garcia, C. F., Silva, A. A. da. (2002). Comparison of GC and HPLC for the quantification of organic acids in coffee. Phytochemical Analysis, 13 (2), 99-104. doi: https://doi.org/10.1002/pca.629

28. AOAC International (1995). Official Methods of Analysis of AOAC International. Secs. 942.15. Washington.

29. AOAC International (2002). Official Methods of Analysis of AOAC International. Secs. 967.21. Washington. 